\title{
Analysis on Linguistic Art of Broadcasting in the New Media Era
}

\author{
Chunli Wang \\ Hongqiqu Executive Leadership Academy, China
}

\begin{abstract}
As the information and communication technology increasingly grows, it is very vital that the new media featuring the internet has blazed a new path for the reform of communication and even the evolution of the whole society. This new era brings opportunities and challenges to traditional media work while facilitating this industry. Efforts should be made to upgrade the broadcasting major in order to meet the requirements of society and the public. This paper aims to explore some problems and difficulties of linguistic art of broadcasting in the new era by analyzing its characters and development trend, so as to ensure the quality of broadcasting programs, and even make sound progress in this era.
\end{abstract}

\section{Index Terms - the new media era, broadcasting, linguistic art, the path of improvement}

The new media sees an extremely unprecedented improvement as the society continuously develops and the internet era increasingly progresses, and the new media also brings a huge impact on the traditional media industry while having a continuous development against the backdrop of the transformation of the public's acceptance mode and their demand. It is the very time that changes should be made to the subjective concept, information sources and presentation mode of the traditional media so as to adapt to the development of the new media era. Meanwhile, broadcast hosts, ones who are responsible for producing and delivering information to the public, play a very essential role in the whole society. Thereby, it needs us to ponder how to improve the linguistic art of broadcasting to cope with the demand for the new media era.

\section{A Brief Introduction of New Media ANd Art of BroadCASting And Hosting}

\section{A. Characteristics of the New Media Era}

The characteristics of the new media era mentioned in this paper are mainly different ones comparing with the traditional media industry. Nowadays, the most salient features in this era include instantaneity, convenience, shareability, magnanimity, individuality and grouping, transience and etc. Instantaneity--receiving and producing information in a real-time, convenience — obtaining information from various ways, shareability —always sharing information with others in some social media, like Wechat moments, vblog, and etc., magnanimity-having information in all aspects from different industries, individuality and grouping - different people holding different opinions in this society, transience - the previous information being replaced by the newly one at a very fast speed, the details shall be showed as follows:

1. It is a kind of instant and two-way process for the public to get as well as to even deliver information. The most tremendous hit taken by new media to the traditional media industry is the break of time and space limitation. Newspaper, paper are the main ways to spread information with the relatively slow speed in the past, resulting in matters to be known only after several hours or even one day. With mobile media, various live broadcasting Apps among others, the public can get the news when it happened just now or is being on in this era. The real-time two-way communication is that publishers of the information can receive feedback directly through WeChat message, bullet screen and other real-time comments from the public, while the public also can search for what they are really interested in on the website. So the public can enjoy the benefits of this two-way communication. This, to a large extent, is an instant and two-way communication of information.

2. Various information can be received in a very convenient way. The news runs from mouth to mouth is the only way for people to get a message in the past. This is a very single method to get information. However, as the appearance of symbols and characters has laid a solid foundation for the preservation and dissemination of information, the public starts to gather more and more information like political events, latest notification, and others through newspapers. One thing is that the public can only read the information passively without extracting the content they really want to focus on. At present, current politics, entertainment, sports, constellation and all aspects of messages are coming to you like all rivers running into the sea as the development of the new media goes deeper. The channels of obtaining information are getting diversified and it becomes more convenient for the public to gather and receive information so that people can choose what they want to know and look for some specific information they really need.

3. Everyone here can provide personalized and various information for others in this era. The public could be receivers of information as well as publishers, and even become the role of the event without knowing. The original publishers including experts, journalists and authorities change to every person in the society, which allows presenting more personalized media information. Meanwhile, media information becomes more diversified and grouping for its producing, publishing and releasing by everyone here. 
4. This massive information with high mobility could be received by a widely-ranged public. It is very convenient for the public to obtain information on the new media era, and the public from the aged to children could search for and collect information by social media, so this is a diversified, rich group. Thereby, the information on social life, military science and technology, entertainment animation and even current political reports has become more colloquial and popular in this condition. Also, life is enriched by this information, sometimes, one piece of news could be replaced very quickly by a piece of another explosive one, which makes the information more mobile. This is transience, the characteristic of the new media era we mentioned above.

\section{B. Linguistic Art of Broadcasting}

In China, a country with a history and civilization of 5,000 years, also has a time-honored long-standing history of language and characters. Although the time of the origin remains unknown, it is confirmable that language has developed maturely early in Yin and Shang Dynasties. By the time "Towards One Chinese Character" in the Qin Dynasty, the characters of the whole nation have reached perfect unity. Promoted by Mandarin Chinese which emerged in the Spring and Autumn Period, language and pronunciation became more unified. After the founding of New China in 1949, China carried out the popularization of Mandarin in the whole country. With the establishment of China National Radio about 60 years ago, requirements for language and pronunciation standards have been proposed and studies on the language of broadcast anchors have been listed on agenda since then.

In real work, particularly in the era of new media, broadcast anchors' verbal language proficiency plays a crucial role in the program broadcasting effect. The work of broadcast anchor, as verbal language artist has the following characteristics:

The broadcast anchor's language must be normative, which requires clear pronunciation, smooth speech, normative language usage, and appropriate verbal expression according to different semantic contexts, relative stressing, slow or fast pronunciation, tone, pause, phonetic changes, etc. while speaking Mandarin very well.

The broadcast anchor's language should have a promoting effect. Not a machine conveying texts with language and voice, broadcast anchor with their own standpoint and attitude should express with sincere emotions and clear position, and play a role of educating, leading and mobilizing the audience. Broadcast language without emotion and incitation only make broadcast work indifferent and ordinary without any vitality. Only after incorporating their own emotions into the broadcasting content can emotional resonance with the content and audience be achieved, thus guiding the audience to judge the right and wrong.

The broadcast anchor's language should be solemn. The broadcast anchor as a public figure under the spotlight of the masses represents the position and image of the program, which requires for their positive energy, reasonable and evidence-based language expression, sincere and plain statement of objective facts, and expression of logical ideas, rather than flaunty, false and empty language.

The broadcast anchor's language should be artistic. The reason why we would like to treat broadcasting as a kind of art is that language used in the broadcasting itself is a kind of artistry, and broadcasting is a unique, distinct and personalized way used by its hosts to disseminate various information to the public so as to give the public a deeper impression and understanding on the information. ${ }^{[1]}$ Broadcasting language in the new media era, with its authentic, creative, standardized, serious, motivated characters, shall be elaborated in the following paper. And how to use these language features in the new media era shall be shown also.

\section{Linguistic FeAtures And Developing Trend of BroAdCAsting in the New Media ERA}

\section{A. Natural Language State}

People are yearning for comfort, free and real-life with the lifestyle-changing fast against the backdrop of the new media era. Announcers and hosts, adhering to the principle of media being the speaker of the Party, are inclined to convey information to the public with their serious expression state and strict, official language state, which means that the public is forced to accept the information to some extent. However, this kind of one-way dissemination has gone away in the new media era as it is more convenient for the public to obtain and express information through various ways and there are various channels for the audience to express their ideas, and they are increasingly selective and critical of the media. So the time in which announcers and hosts delivered information and the public received it unilaterally has passed away. They change their original rigid expression state to a more natural, amiable language expression so as to meet the public needs, improve the program rating, enhance the emotional resonance by narrowing their mental distance, and then facilitate the trust in the program.

\section{B. Personalized Language Style}

Nowadays, the monopoly in the traditional industry is not welcomed in this new era. Various social media produce impressive, eye-catching information by using all kinds of methods in order to receive the public's clicks. The host, which is the soul and best example of a personalized program, could have a definite impact on how much the audiences can accept the information, program, and even the channel through the language expression art.

As it demonstrated in a Ph.D. dissertation Research on Transformation and Upgrading of Master of Ceremonies under All Media Era in China written by Chen Siyang, from Tianjin Normal University, announcers and hosts stand for the art of communication, the art of language, and also the art of programs integration and public opinion guiding, so it calls for 
clear, effective dissemination from one to the public. The hosts with only imitation of other styles in their hosting work and lacking their own individuality and characters are destiny to fade away in the era of Omnimedia, where the public has numerous choices. ${ }^{[2]}$ So these announcers and hosts with these old-fashioned, routine language expression styles cannot satisfy the public's tastes and would be forgotten in this new era. Only keeping in learning, innovating to become more thoughtful and personalized, they could not be missed by the public with digging out the preference of the public and showing the language charm.

\section{Fashionable Language Performance}

It is no desire for some audience to watch traditional, dull broadcasting with some drafts amid the development of information, fragmentation, and entertainment. Broadcast hosts need to learn how to use some new fashionable words to make an adaptation of the whole society and gain more attraction from the targeted audience. Certainly, instead of adopting all, they should sort out the most popular words which conform to the core values of this time and the social mainstream. Furthermore, they can also create new popular words to gain recognition from the public during the process of language expression. This is what the announcers and hosts can do to improve their personal charms as well as facilitating the novelty of the program.

\section{Problems of the Linguistic Art of BroadCAsting in the New Media ErA}

As modern society continuously grows, people now enjoy a diversified, fast-paced and informationized lifestyle. The news delivered by some of these broadcast announcers and hosts is just for catching the attention of the public. Without adhering to the principle of language expression art, some hosts may have some vulgar language expression and non-mainstream values to satisfy the curiosity of the targeted audience, and even to addict to the reckless pursuit of program ratings only. What kind of poor actions they may do are as follows:

\section{A. Non-standard Language Expression}

The broadcast announcers and hosts shall adhere to the basic occupational principle of the standard language expression in their daily creation work and performance. As everyone becomes the producer of events, the publisher of information in this new media and self-media era, the public has more and more choices. Some announcers and hosts start to host entertainment programs with vulgar, uncouth language, broadcast sports events with the coarse, violent ones and even use entertaining words in normal new reports so as to cater to the public's taste and pursue the program ratings. All the above results in the lack of standard language expression of broadcast hosts, effecting the program quality directly.

Some efforts should be made by some other broadcast hosts to improve their own professional literacy as some basic mistakes are made in their daily work. Firstly, some may not have a comprehensive understanding of the meaning of the word. Here is an example, "shenshenxuezi" in Chinese is a group unit noun, representing a great number of students, but some hosts may use it with a quantifier. Secondly, some idioms are misused in some places. For example, "Xianduweikuai" in Chinese means that someone hurries to have a glimpse of the book before publishing or the TV show before broadcasting. Super Variety Show produced by CCTV had a program introducing Tibet in June 19, 1999. The program was well-received by the audience, so some parts of this program would be showed again in this show. Because of the content being arranged for the very beginning of this show, the host told the audience that let's have a glimpse into it before the program starting. This is the misuse of this idiom.

Actually, no matter how the world changes, it is very essential for these broadcast announcers and hosts to insist on language regulation, showing a direct landscape of a whole group, program and even the whole country. Therefore, the group needs to focus on the regulation of language in the new media era, not just seeing the woods for the trees.

\section{B. Unreal Language Content}

The reality is the very core for news reports and all information. The public are not just fond of the novel, interesting information, but also their authenticity. However, nowadays some media and broadcast hosts start to miss the quality in order to achieve higher ratings.

Some publishers are more likely to produce the event and even makeup it according to subjective assumptions without having a better understanding of the whole thing in this fast-paced information processing world. Broadcast announcers and hosts cannot learn whether the information is accurate, authentic or not, sometimes they even deliver the false one in order to attract the public's attention. Especially, headlines, such as celebrity extramarital affair, two famous stars falling in love, are made to attract the public in some entertaining reports. And even some hosts would like to report some fake news to gain in popularity. It is a vicious cycle for this industry, at last, the truth is not of the significance, instead, eye-catching news prevails. So there is not true, timely news any more finally. What's worse, what these broadcast hosts report influences not only the public's cognition but also their daily production, leading them to distrust the reporting information. This is one of the shortcomings of the new media era. It has an extreme impact on the audience to accept such unreal, fast-paced language content, so they are more likely to just listen for fun and even start to have a question on the objectivity and impartiality of the media.

\section{Lack of Initiative in Fashioning Language}


The requirements for the linguistic art of broadcast announcers and hosts in the new media era are new, curious and unique, which means they need to foster their own language style. Many hosts are unable to catch up with steps with this fast-changing world and make proper adjustments. They always prefer to choose the same, invariable working modes, stereotyped, routine language style, and even boring expression pattern without any changing. However, as the world and people's self-consciousness improves, a growing vast of people begin to wish for hosts reporting the news with their own personal charming, instead of this traditional way of infusing information. It is a question for every broadcast announcers and hosts to ponder how to establish a unique language style and improve their personal charm against the backdrop of this extremely complex and changing environment. Recently, it can be found in the latest program news anchors talking about hot news in which some hosts from CCTV's national news program "Xinwen Lianbo" or News Broadcast, advocate positive energy through a more personalized, emotional basis which never happened before. It is a vivid trial to explore how to fashion language in this modern society.

\section{Steps made to Further the Linguistic Art of Broadcasting in the New Media Era}

\section{A. Moving forward with the Positive Energy of the Society by Improving Self-cultivation}

Language plays the most influential role in the development of the new media era and even the whole world. As we all know that all kinds of information nowadays has rushed into the public in the world of internet and digitalization. It is one of the most important responsibilities for broadcast announcers and hosts to deliver the social mainstream culture and show positive energy by sorting out meaningful information for the public with their cognition. So they should catch up steps with the world to get their self-cultivation improved, which includes political and moral cultivation, ideological and cultural improvement, professional knowledge education and other aspects to learn how to advocate the social mainstream culture and make innovation for the program. At the same time, it also needs these excellent talents to establish a sound language style. Rather than trying new things in form only, more importantly, the core values of morality should be introduced to the language of broadcasting, giving emphasis on the content quality of the broadcasting and hosting language, and even digging out the truth, kindness, and beauty from their inner hearts. ${ }^{[3]}$ It is the incumbent responsibility of the contemporary broadcasting announcers and hosts to promote the ideological, moral taste of the public through their own value tastes and language styles, and even to advocate the socialist core values and positive energy. What makes us delighted is that some broadcast hosts already have a better understanding of this point in this new era. The model of the times, a new program produced by CCTV, select and report some typical exemplars of the advanced figures, and invite them to the prize presentation. These impressive stories are presented by these hosts with standardized language, emotional words, and patriotism from the inner heart to the audience, leading to a strong admiration of the models while listening to the stories. All the above are the charm of language, as well as a new exploration of the themes, subjects, reporting modes and language expression by media and broadcast hosts in this new era.

\section{B. Working Hard to Form a Better Broadcasting Style with a Sound Language Consciousness}

A popular saying goes "a good look is all alike, while an interesting soul is one in a million", comparing to the traditional broadcasting with scripts in the traditional media industry, the public call for excellent hosts who always hold their own points towards what they report and who always have their true disposition, not just the basic requirements of sound pronunciation and full tone in the new media era. So as broadcast announcers and hosts, what they really need to do is to establish a better language consciousness and to form their own unique broadcasting style. There are two targets they should pursue in their work. In the first place, efforts should be made for these announcers and hosts to learn healthy language content, expression, and art, combine with their own experience and understanding and then innovatively apply to own programs against the backdrop of market information and diversification. It should be noted that some hosts want to meet the requirements of the public by imitating the language style of some non-mainstream internet celebrities. This may work in the short term for improving the program ratings, but not a long-term solution. This is what we called taking the essence while discarding the dregs. Then, they should insist on a firm principle of responsibility, which means announcers and hosts should be encouraged to make emotional communication with the targeted group through words and deeds and the charm of language, as they are responsible for producing the right program content, showing the correct social morality and practicing the social harmony. As a result, new ideas and positive energy could be brought to the targeted audience. Efforts are made to enrich their cultural knowledge, ideological realm and other continuous accumulation, these hosts can convey their own points and voices with unique, sound language style to the public while delivering information. This would be welcomed by the public.

\section{Pressing Ahead with a Stronger Interaction by Improving the Affinity of Linguistic Art of Broadcasting}

Affinity has the power to draw people close and further establish emotions. In the era of new media, in front of intricate and complex social information, the audiences can choose the information they want more independently. A broadcast anchor with amiable language can attract the attention of the audience, and make the audience have the intention of "follow and keep watching", thus improving the audience rating of the program.

Therefore, under the premise of catching the mainstream ideology, more attention shall be paid by the announcers and hosts to the cognition and psychological process of the audience in the new media ear, which means that hosts need to 
learn how the audience thinks, what they are really worried about, and especially make emotional communication with them.

Announcers and hosts should frequently use respectful words, honorific titles and sincere tone to show your respect for the public. When the public feel the respect from hosts, gain goodwill would be given to announcers and hosts. ${ }^{[4]}$ Only in this way can they just put down their psychological resistance and even accept what these hosts deliver from the bottom of their heart. Meanwhile, with the perspective of the audience to think about the problem, hosts can learn their reaction after hearing the information, make adjustments of the content, speed and tone, as well as integrate their deep emotions into the language, so as to make the program more appealing.

\section{CONCLUSION}

The new era calls for new requirements for the language expression of broadcasting. Broadcasting hosts should play a very vital role in how to ensure that the information provided is accurate, how to disseminate valuable information to the public, how to advocate positive energy and right social values, how to set up sound social morality and even to guide public opinion. Above these, they, as qualified announcers and hosts, also need work to facilitate language expression to show its charm and further a sound, healthy broadcasting art in the new media era. ${ }^{[5]}$ Meanwhile, some relevant adjustment, regulation, and improvement should be made to make a vivid, healthy linguistic art in the new media era. All this means that it is still a long way to go. Also, it is believed that more impressive programs shall be made for the public in the future with the support and promotion of all social communities as well as the hard work of these hosts.

\section{REFERENCES}

[1] Chen Siyang. (2016). Research on Transformation and Upgrading of Master of Ceremonies under All Media Era in China: Tianjin Normal University, 6, 16-17.

[2] Chan Zhao, Peijian Paul Sun. (2019). Doing Research in Applied Linguistics: Realities, Dilemmas, and Solutions. Australian Journal of Linguistics, 4, 38-39.

[3] Lian Shaopeng. (2017). Analysis on Linguistic Art of Broadcasting in the Context of New Media: Journal of News Research, 4 , 136-138.

[4] Wang Lei. (2015). Linguistic Art of Broadcasting in the New Media Era: Journal of News Research, 12, 115-117.

[5] Wang Shoujiang. (2019). Analysis on Linguistic Art of Broadcasting in the New Media Era: West China Broadcasting TV, 7,158-160.

Chunli Wang was born in Anyang, China in 1991. She received her Master of Arts degree in arts of broadcasting and anchoring from Hennan University, China in 2017.

She is currently a lecturer in the Hongqiqu executive leadership academy of Spirit of red flag canal. Her research interests include linguistics and pedagogy.

Ms.Wang is a member of the Red flag canal spirit research institute. 